\title{
Grosgrain and elastic stockings for the reduction of lymphedema and the maintenance of the results of treatment
}

\author{
Renata Lopes Pinto ${ }^{1}$, Maria de Fatima Guerreiro Godoy ${ }^{2}$, and Jose Maria Pereira de \\ Godoy $^{3}$ \\ ${ }^{1}$ Clínica Godoy \\ ${ }^{2}$ Clinica Godoy \\ ${ }^{3}$ Faculdade de Medicina de Sao Jose do Rio Preto
}

May 5, 2020

\begin{abstract}
Aim: The aim of the present study was to evaluate the use of grosgrain and elastic stockings for the treatment of lower limb lymphedema and maintenance of the results. Method: Twenty-two consecutive patients who made use of grosgrain stockings for the treatment of lower limb lymphedema until normalization or near normalization of the limb, followed by the use of elastic stockings for the maintenance of the results. Evaluations were performed using volumetric analysis. This study involved patients with bilateral primary lower limb lymphedema located below the knee who used grosgrain stockings as monotherapy to achieve normalization or near normalization of leg volume and then began to use elastic compression stockings $(30 / 40 \mathrm{mmHg})$ for the maintenance of the results. Results: A significant reduction in volume occurred with the use of the grosgrain stockings $(\mathrm{p}<0.0001$, paired t-test) and a significant increase occurred with the use of elastic stockings $(\mathrm{p}=0.04)$. Grosgrain stockings are better than elastic stockings for the reduction in lymphedema. Conclusion: Elastic stockings are useful in maintaining the results, but must be combined with other forms of therapy for the significant mobilization of macromolecules.
\end{abstract}

\section{Hosted file}

Grosgrain and elastic stockings for the reduction of lymphedema and the maintenance of the results of $t$ available at https://authorea.com/users/300800/articles/430529-grosgrain-and-elasticstockings-for-the-reduction-of-lymphedema-and-the-maintenance-of-the-results-oftreatment 

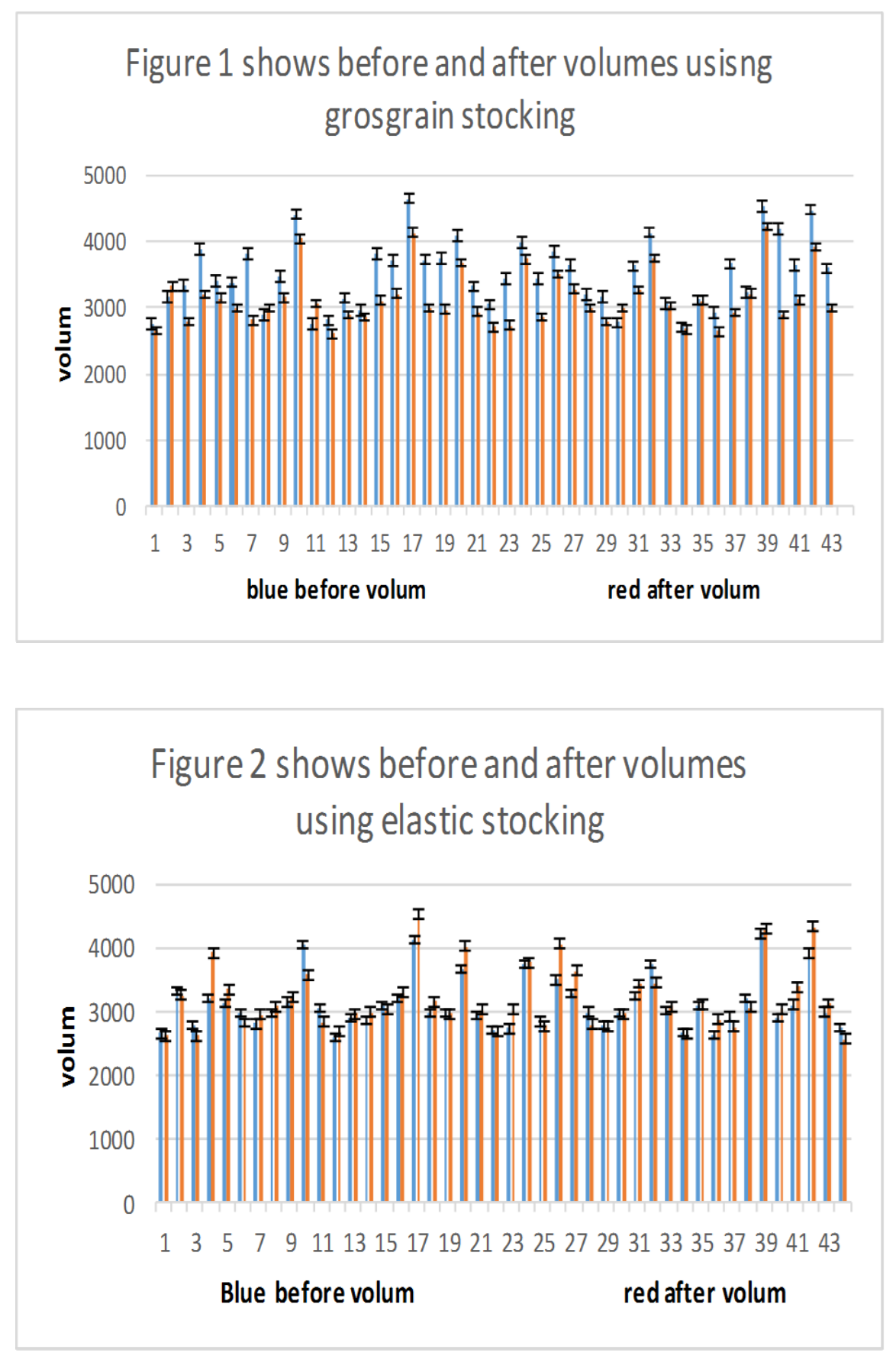